\title{
Effects of Paper Mulberry Silage on the Growth Performance, Rumen Microbiota and Muscle Fatty Acid Composition in Hu Lambs
}

\author{
Yi Xiong ${ }^{1} \oplus$, Chunze Guo ${ }^{1}$, Lin Wang ${ }^{2}$, Fei Chen ${ }^{1}$, Xianwen Dong ${ }^{2}$, Xiaomei Li $^{1}$, Kuikui Ni $^{1}$ and Fuyu Yang ${ }^{1, *}$ \\ 1 College of Grassland Science and Technology, China Agricultural University, Beijing 100193, China; \\ xiongleslie@126.com (Y.X.); guocz19970404@163.com (C.G.); 17683267025@189.cn (F.C.); \\ b20193040360@cau.edu.cn (X.L.); nikk@cau.edu.cn (K.N.) \\ 2 Chongqing Academy of Animal Sciences, Chongqing 402460, China; wcrwl681031@163.com (L.W.); \\ dxwcqxky@163.com (X.D.) \\ * Correspondence: yfuyu@126.com; Tel.: +86-010-62733-052
}

check for

updates

Citation: Xiong, Y.; Guo, C.; Wang, L.; Chen, F.; Dong, X.; Li, X.; Ni, K.; Yang, F. Effects of Paper Mulberry Silage on the Growth Performance, Rumen Microbiota and Muscle Fatty Acid Composition in Hu Lambs. Fermentation 2021, 7, 286. https://doi.org/10.3390/

fermentation7040286

Academic Editor: Zhiming Rao

Received: 8 November 2021

Accepted: 26 November 2021

Published: 28 November 2021

Publisher's Note: MDPI stays neutral with regard to jurisdictional claims in published maps and institutional affiliations.

Copyright: (c) 2021 by the authors. Licensee MDPI, Basel, Switzerland. This article is an open access article distributed under the terms and conditions of the Creative Commons Attribution (CC BY) license (https:/ / creativecommons.org/licenses/by/ $4.0 /)$.

\begin{abstract}
Paper mulberry (Broussonetia papyrifera) is widely ensiled to feed sheep in southwestern China, as unconventional woody forage. Feeding lambs with paper mulberry silage (PMS) may improve certain feeding characteristics, thereby affecting the growth performance and meat quality. The aim of this study is to investigate the effects of four diets of PMS on growth performance, rumen microbial composition, and muscle fatty acids profile in Hu lambs. The results showed that $30 \%$ and $40 \%$ PMS increased the dry matter intake and average daily gain of $\mathrm{Hu}$ lambs compared to the control group. PMS30 and PMS40 increased the content of C24:1, and PMS40 increased the content of C20:5n-3. The content of microbial protein (MCP) was higher in PMS40 than in others, but PMS30 and PMS40 reduced the total volatile fatty acid in rumen. PMS30 significantly increased the ratio of acetic acid to propionic acid. The abundance of ruminal Christensenellaceae_R-7_group and norank_f_Eubacterium_coprostanoligenes_group was significantly higher in PMS30 and PMS40 groups. Moreover, Christensenellaceae_R-7_group had a significant positive correlation with n3-polyunsaturated fatty acid. PMS40 might lead to a relatively high content of unsaturated fatty acids in longissimus dorsi muscle by increasing the relative abundance of Christensenellaceae_R-7_group in rumen.
\end{abstract}

Keywords: paper mulberry; silage; lambs; rumen bacteria; fatty acids

\section{Introduction}

Sheep are thought to be the first domesticated livestock species and thus integral to animal husbandry [1]. China has experienced a significant economic growth in recent decades, and the growing consumption of mutton is leading to increased lamb production and sheep meat import. China is now the largest importer of sheep and goat meat in the world, with a volume forecast to reach 1.38 million metric tons in 2021 [2]. As the structure of meat consumption changes, numbers of domestic animal husbandry enterprises have seized this development opportunity, and at the same time due to the strategy of rural vitalization, the scale and technology of animal husbandry have been continuously updated. Hu sheep are widely farmed in southern China because of their high reproductive performance (Multiple fetuses) [3]. However, the main constraint for further improvement of lamb products is the lack of adequate and high-quality feed stuff [4,5]. Large amounts of forage are consumed by cattle and sheep, and the global trade of fodder has been limited due to the pandemic of COVID-19. Sino-US economic- and trade frictions have continued in the past few years, which have worsened the shortage of quality forages in domestic. Consequently, considerable interest has been given to the use of paper mulberry [6,7], a woody grass which could enjoy a broad array of uses for meeting the challenge of food-fuel-feed competition [8], available substitution for enhancing lamb performance. 
Paper mulberry, with its relatively high content of protein, has been used as a substituted feedstuff of protein [7], especially with the current shortage of quality forage and soybean meal. Although the abundant rainfall in southern China can provide a large amount of biomass for paper mulberry, the rainfall makes it difficult to store feed after harvest. Consequently, ensiling is a way to store fresh plants which avoids excessive energy consumption (used for drying in rainy southern China) and improves the palatability of feed with lactic acid fermentation under anaerobic conditions $[4,9,10]$.

Paper mulberry contains higher condensed tannin [11], which may positively affect the meat quality of livestock products by altering the rumen's fermentation mode $[8,12,13]$ and the biohydrogenation of unsaturated fatty acids. Moreover, paper mulberry can improve the milk quality of dairy cattle and the meat quality of sheep [14,15], change the rumen microorganism [16], and increase the content of polyunsaturated fatty acids in milk $[17,18]$. However, few studies have focused on the relationship between rumen microorganisms and meat quality [19].

Therefore, this study explored the relationship between a diet of paper mulberry silage with lamb meat quality and rumen fermentation. We hypothesized that paper mulberry silage could help to improve the quality of lamb meat. We closely examined the effects of paper mulberry silage on the meat quality of Hu sheep, including correlations between rumen bacteria flora and fatty acid composition which have previously received little attention.

\section{Materials and Methods}

\subsection{Diets, Animals, and Experimental Design}

The experiment was conducted in accordance with the Chinese Guidelines for Animal Welfare and Experimental Protocol, and approved by the Animal Care and Use Committee of China Agricultural University (ID:AW22601202-5-1).

Paper mulberry (B. papyrifera) were harvested in the third cutting and ensiled by Rongcheng Gouyang Modern Agriculture Co., Ltd. which is located in Rongchang, Chongqing, China $\left(29^{\circ} 51^{\prime} \mathrm{N}\right.$ and $105^{\circ} 49^{\prime} \mathrm{E}$ ). The location has a subtropical monsoon climate. This study was also conducted on the farm of Rongcheng Gouyang Modern Agriculture Co., Ltd., and lasted for $56 \mathrm{~d}$, with the first week for a preliminary trial period followed by 7 weeks of paper mulberry silage (PMS) treatment, beginning on 3 December 2020 and finishing on 28 January 2021. Forty weaned lambs (approximately 45-days old) were randomly divided into four treatments individually: control group, 20\% (PMS20), 30\% (PMS30), and 40\% (PMS40). Four diets were formulated according to the values recommended by the Feeding Standard of Meat-Producing Sheep of Chinese agricultural industry standards (NY/T 816-2004) and produced as a total mixed ration (Table 1). The nutrient and chemical composition of PMS diets were shown in Table 1. The environment was comfortable and equipped with ventilation and moisture-proof measures. All lambs were fed twice a day (08:00 and 18:00), allowed to feed ad libitum, and given free clean water throughout the entire experimental period.

\subsection{Sample Collection, Carcass Characteristics and Meat Quality Measurement}

Body weight was recorded individually on the first day and at the end of the feeding experiment, and during the feeding period, feed offered and refused was quantified to determine dry matter intake (DMI) daily. Before slaughter, lambs were prevented from consuming feed and drinking for $12 \mathrm{~h}$ All lambs were recorded after all blood samples (for serum biochemical analysis) were collected and hot carcasses were weighted. We use an electronic platform scale with an accuracy of $10 \mathrm{~g}$. The whole rumen contents of each $\mathrm{Hu}$ lamb was mixed immediately, and then squeezed through four layers of cheesecloth to separate liquid fractions and $\mathrm{pH}$ of rumen was recorded (PHS-3C with three-point calibration). Then they were collected into three $15 \mathrm{~mL}$ sterilized tubes and put into liquid nitrogen. All rumen microbe samples were stored at $-80^{\circ} \mathrm{C}$ before the volatile fatty acid and $16 \mathrm{~S}$ rRNA gene analysis. Forty-five minutes after slaughter, longissimus dorsi (LD) 
muscle of lambs were collected from carcass for meat color, $\mathrm{pH}$, drip loss, cooking loss, and shear force data measurement.

Table 1. Ingredients and chemical composition $(\mathrm{g} / \mathrm{kg}$, dry matter basis) of treatments.

\begin{tabular}{|c|c|c|c|c|c|}
\hline Items (DM Basis) & Control & PMS20 & PMS30 & PMS40 & Paper Mulberry Silage \\
\hline \multicolumn{6}{|l|}{ Ingredients $(\mathrm{g} / \mathrm{kg})$} \\
\hline Corn powder & 248 & 253 & 261 & 274 & / \\
\hline Soybean meal & 100 & 71 & 59 & 50 & / \\
\hline Wheat bran & 150 & 180 & 185 & 182 & / \\
\hline Corn stover & 483 & 284 & 183 & 83 & / \\
\hline Paper mulberry silage & 0 & 200 & 300 & 400 & / \\
\hline Calcium carbonate & 8 & 1 & 1 & 0 & / \\
\hline $\begin{array}{l}\text { Minerals and } \\
\text { vitamin premix }\end{array}$ & 5 & 5 & 5 & 5 & / \\
\hline salt & 6 & 6 & 6 & 6 & / \\
\hline \multicolumn{6}{|l|}{ Chemical composition (\%) } \\
\hline Dry matter & 86.60 & 74.74 & 68.54 & 62.26 & 28.67 \\
\hline Crude protein \%DM & 13.16 & 13.13 & 13.13 & 13.11 & 9.84 \\
\hline Acid detergent fiber $\% \mathrm{DM}$ & 28.40 & 25.99 & 24.67 & 23.31 & 35.39 \\
\hline $\begin{array}{l}\text { Neutral detergent } \\
\text { fiber } \% \mathrm{DM}\end{array}$ & 46.82 & 42.34 & 39.69 & 36.81 & 43.79 \\
\hline $\begin{array}{c}\text { Metabolizable energy } \\
\mathrm{MJ} / \mathrm{kg}\end{array}$ & 8.94 & 9.56 & 9.86 & 10.16 & 8.21 \\
\hline Calcium & 0.22 & 0.38 & 0.45 & 0.53 & 1.12 \\
\hline Phosphorus & 0.44 & 0.47 & 0.48 & 0.49 & 0.25 \\
\hline
\end{tabular}

Control: dietary without paper mulberry silage, PMS20: dietary with 20\% paper mulberry silage, PMS30: dietary with $30 \%$ paper mulberry silage, PMS40: dietary with $40 \%$ paper mulberry silage.

Measurements of muscle $\mathrm{pH}$ were made after postmortem using a $\mathrm{pH}$ meter $(\mathrm{pH}$ STAR, MATTHAUS, Berlin, Germany). The meat color of LD was measured at $45 \mathrm{~min}$ postmortem by a mean of three random readings made with a portable chromameter (CR-400, Konica Minolta, Tokyo, Japan), which was calibrated with a white tile according to the manufacturer's manual. The light was Illuminant D-65, the inclination Angle is 10, and the aperture radius is $10 \mathrm{~mm}$. The drip loss percentage was measured as per the method previously described [20]. Cooking loss was determined by Cardoso's method [21]. Briefly, muscle samples were heated in $80{ }^{\circ} \mathrm{C}$ water until the central temperature reached $75{ }^{\circ} \mathrm{C}$, after which the samples were immediately removed from the steamer, and reweighed after cooling [21]. Shear force was evaluated after muscle cooking loss were calculated. Three cylindrical cores $(12.7 \mathrm{~mm})$ were removed from cooled muscle samples to the fiber direction [22]. Each sample was sheared using a muscle shear force measuring analyzer (C-LM3B, TENOVO, Beijing, China).

\subsection{Fermentation Characteristics and Volatile Fatty Acid Profile Measurement}

Rumen fluid thawed at $4{ }^{\circ} \mathrm{C}$, then the supernatant was centrifuged at $3000 \mathrm{rpm} \cdot \mathrm{min}^{-1}$ and the content of ammoniacal nitrogen (AN) was determined by the microplate testing system (SpectraMax iD5, Molecular Devices, Pleasanton, CA, USA). Thereafter, 25\% (wt/vol) metaphosphoric acid was added in the supernatant samples and preserved at $-4{ }^{\circ} \mathrm{C}$ for the measurement of ruminal volatile fatty acid (VFAs). The concentrations of VFAs were determined by gas chromatography (Shimadzu, Kyoto, Japan). The Coomassie Brilliant Blue G-250 assay was employed to measure the microbial protein content in the rumen liquid.

\subsection{Serum Biochemical Analysis}

Blood was sampled from a jugular vein of each animal using $10 \mathrm{~mL}$ serum tubes at 08:00 before slaughtering. The blood was centrifuged at room temperature (10 $\mathrm{min}, 2810 \mathrm{~g})$, and the upper serum was obtained and stored at $-20{ }^{\circ} \mathrm{C}$ [23]. Samples were aliquoted for measurement via an automatic biochemical analyzer (CLS880, Zechengbio, Guangzhou, China), which included the measurement of growth hormone (GH), insulin (INS), glucose 
(GLU), total cholesterol (TC), triglyceride (TG), high-density lipoproteins (HDL), lowdensity lipoproteins (LDL), non-esterified fatty acid (NEFA), and leptin (LEP).

\subsection{Analysis of the Amino Acid Composition}

Samples of 50-100 mg were extracted with $0.5 \mathrm{~mL} 0.1 \mathrm{M}$ hydrochloric acid for $1 \mathrm{~h}$ with gentle agitation on a shaker at room temperature. Each sample was filtered through a $0.22 \mu \mathrm{m}$ pore membrane filter. Then $10 \mu \mathrm{L}$ of the sample was taken into a UHPLC vial and added $70 \mu \mathrm{L}$ Borate buffer and $20 \mu \mathrm{L}$ AccQ Tag reagent. The reaction mixture was kept at room temperature for $1 \mathrm{~min}$, heated at $55^{\circ} \mathrm{C}$ for $10 \mathrm{~min}$ and $1 \mu \mathrm{L}$ was injected after cooling. The sample extracts were analyzed using an UPLC- Orbitrap-MS system (UPLC, Vanquish; MS, QE). The analytical conditions were as follows, UPLC: column, Waters BEH $\mathrm{C} 18(50 \times 2.1 \mathrm{~mm}, 1.8 \mu \mathrm{m})$; column temperature, $55^{\circ} \mathrm{C}$; flow rate, $0.5 \mathrm{~mL} / \mathrm{min}$; injection volume, $1 \mu \mathrm{L}$; solvent system, water $(0.1 \%$ Formic acid): acetonitrile $(0.1 \%$ Formic acid); gradient program, 95:5 $v / v$ at $0 \mathrm{~min}, 90: 10 v / v$ at $5.5 \mathrm{~min}, 75: 25 \mathrm{v} / \mathrm{v}$ at $7.5 \mathrm{~min}, 40: 60 \mathrm{v} / \mathrm{v}$ at $8 \mathrm{~min}, 95: 5 v / v$ at $8.5 \mathrm{~min}$, and $95: 5 v / v$ at $13 \mathrm{~min}$. HRMS data were recorded on a $\mathrm{Q}$ Exactive hybrid Q-Orbitrap mass spectrometer equipped with a heated ESI source (Thermo Fisher Scientific, Waltham, MA, USA) using the SIM MS acquisition methods. The ESI source parameters were set as follows: spray voltage, $3 \mathrm{kV}$; sheath gas pressure, $40 \mathrm{arb}$; aux gas pressure, $10 \mathrm{arb}$; sweep gas pressure, $0 \mathrm{arb}$; capillary temperature, $320^{\circ} \mathrm{C}$; and aux gas heater temperature, $350^{\circ} \mathrm{C}$. Data were acquired on the Q-Exactive using Xcalibur 4.1 (Thermo Scientific, Waltham, MA, USA), and processed using TraceFinder ${ }^{\mathrm{TM}} 4.1$ Clinical (Thermo Scientific, Waltham, MA, USA). Quantified data were output into excel format.

\subsection{Analysis of the Fatty Acid Composition}

Samples of LD were collected to measure fatty acid composition. The fatty acid composition in the meat was determined using gas chromatography-mass spectrometric (GC-MS) according to the methods described in previous studies. Thirty-seven fatty acid methyl esters were used as mixed standard samples for quantitative analysis [22]. Lipids were extracted from the meat samples using the trichloromethane and dichloromethane, successively. Then, free fatty acid mixture was esterified with $2 \mathrm{~mL}$ methylation reagent. After shaking for $30 \mathrm{~s}$, the mixture was reacted in $80^{\circ} \mathrm{C}$ water for $2 \mathrm{~h}$. Fatty acid methyl esters were analyzed using an Agilent 6890 gas chromatographer equipped with a flame ionization detector (Agilent Technologies, Santa Clara, CA, USA). A CP-Sil 88 fused silica open tubular capillary column $(100 \mathrm{~m} \times 0.25 \mathrm{~mm} \times 0.25 \mu \mathrm{m})$ was used. The initial oven temperature was set at $100{ }^{\circ} \mathrm{C}$ for $5 \mathrm{~min}$ and increased to $240{ }^{\circ} \mathrm{C}$ at $4{ }^{\circ} \mathrm{C} / \mathrm{min}$, kept at $240{ }^{\circ} \mathrm{C}$ for $5 \mathrm{~min}$, then increased to $350^{\circ} \mathrm{C}$ at $15^{\circ} \mathrm{C} / \mathrm{min}$. The carrier gas was helium at a flow rate of $1 \mathrm{~mL} / \mathrm{min}$. The mass spectrometric system is the quadrupole mass spectrometric detection system (Agilent 5977; Agilent Technologies, Santa Rosa, CA, USA) with electron bombardment ion source (EI) and Mass hunter workstation. The fatty acid was detected by the electron bombardment ion source (EI) fully SCAN mode. The optimized conditions of mass spectrometry analysis were as follows: inlet temperature $260^{\circ} \mathrm{C}$, quadrupole temperature $150{ }^{\circ} \mathrm{C}$; Scanning mode is full SCAN mode, mass scanning range $(\mathrm{m} / \mathrm{z})$ : 30-550. The identification of individual fatty acid methyl esters was accomplished by the retention times of an authentic standard. The concentration of individual fatty acids was quantified according to the peak area and expressed as a percentage of total fatty acids.

\subsection{DNA Extraction, $16 \mathrm{~S}$ rRNA Gene Amplification, and High-Throughput Sequencing}

DNA of the rumen liquid samples was extracted using the bead-eating and phenolchloroform extraction method. The quality and concentration of the extracted DNA were measured on a NanoDrop2000 spectrophotometer. Then, polymerase chain reaction (PCR) was used to amplify the V3-V4 region of the bacterial $16 \mathrm{~S}$ rRNA gene using primers $338 \mathrm{~F}$ (5'-ACTCCTACGGGAGGCAGCA-3') and 806R (5'-GGACTACHVGGGTWTCTAAT-3'), and specific primers with Barcode were synthesized according to the specified sequencing region. The PCR condition was set as follows: initial denaturation at $95{ }^{\circ} \mathrm{C}$ for $2 \mathrm{~min}$, 
25 cycles of denaturation at $95{ }^{\circ} \mathrm{C}$ for $30 \mathrm{~s}$, annealing at $55^{\circ} \mathrm{C}$ for $30 \mathrm{~s}$, elongation at $72{ }^{\circ} \mathrm{C}$ for $30 \mathrm{~s}$, and extension at $72{ }^{\circ} \mathrm{C}$ for $5 \mathrm{~min}$. Each treatment was conducted in triplicate and the mixture was purified to perform sequencing. PCR products were verified on agarose gel $(2 \%, w / v)$, and the expected bands were extracted separately and purified via the Axy-PrepDNA Gel Extraction Kit. The concentrations of the purified DNA amplicons were quantified using Quantifluor ${ }^{\mathrm{TM}}$-ST Blue Fluorescence Quantitative System. Amplicons from different samples were mixed in equal ratio and sequenced via the $2 \times 300$ paired-end kit on an Illumina MiSeq platform. Any sequences with mismatches and ambiguous reads in the primers were removed for quality-control purposes.

\subsection{Statistical Analysis}

All data obtained in the present study were analyzed using One-Way Analysis of Variance (ANOVA) to determine different dietary treatments, and Duncan's multiple range test was conducted to post hoc analyses via IBM SPSS 24.0 software (IBM Co., Armonk, NY, USA). Statistically significant difference was set at $p<0.05$. Spearman correlation analysis was used to relate the abundance of the top 50 bacterial genera with the content of free amino acids and fatty acids using $\mathrm{R}$ (version 3.3.1). Only correlations with $p<0.05$ for the linear model were considered as significant.

\section{Results}

\subsection{Growth Performance, Carcass Characteristics, and Meat Quality}

As shown in Table 2, PMS30 increased average daily gain compared to the control group and PMS20 ( $p$ 0.05). PMS40 significantly increased dry matter intake compared to the control group $(p<0.05)$, and there was no difference among PMS20, PMS30, and PMS40. However, dietary paper mulberry silage (regardless the ratio of ration) had no effects $(p>0.1)$ on carcass weight, compared to control. Though PMS30 increased L*(lightness) and $\mathrm{a}^{*}$ (redness) of longissimus dorsi (LD), significant difference between treatment was not detected. Besides, treatments had no effects $(p>0.1)$ on $\mathrm{pH}$, drip loss, cooking loss, or shear force in LD muscle.

Table 2. Effect of dietary paper mulberry silage on the growth performance, carcass characteristics and longissimus dorsi (LD) quality of Hu lambs.

\begin{tabular}{ccccccc}
\hline Item & Control & PMS20 & PMS30 & PMS40 & SEM & $p$-Value \\
\hline Initial body weight, $\mathrm{kg}$ & 14.64 & 15.52 & 14.82 & 15.06 & 0.5482 & 0.433 \\
Final body weight, kg & 19.18 & 21.04 & 21.75 & 21.85 & 1.5775 & 0.276 \\
Dry matter intake & $0.7241 \mathrm{~b}$ & $0.765 \mathrm{~b}$ & $0.7817 \mathrm{ab}$ & $0.8274 \mathrm{a}$ & 0.0306 & 0.010 \\
Average daily gain, $\mathrm{kg}$ & $0.0927 \mathrm{~b}$ & $0.1127 \mathrm{ab}$ & $0.15 \mathrm{a}$ & $0.1311 \mathrm{ab}$ & 0.0240 & 0.009 \\
Hot carcass weight, kg & 9.67 & 11.13 & 9.93 & 10.13 & 0.6823 & 0.232 \\
Carcass yield, \% & 45.48 & 48.01 & 44.45 & 45.14 & 1.3878 & 0.132 \\
Colour L* & 33.86 & 33.85 & 36.56 & 33.21 & 2.8303 & 0.239 \\
Colour a* & 57.58 & 59.89 & 61.24 & 54.93 & 3.6312 & 0.089 \\
Colour b* & 11.46 & 12.12 & 12.10 & 10.60 & 1.1680 & 0.248 \\
pH & 6.87 & 7.00 & 6.91 & 6.67 & 0.2037 & 0.452 \\
Drip loss, \% & 0.67 & 0.71 & 0.56 & 0.49 & 0.3705 & 0.074 \\
Cooking loss \% & 41.20 & 39.19 & 39.29 & 41.30 & 1.8934 & 0.551 \\
Shear force, $\mathrm{kg}$ & 6.0560 & 5.4280 & 5.1243 & 3.9800 & 1.1096 & 0.361 \\
\hline
\end{tabular}

Control: dietary without paper mulberry silage, PMS20: dietary with $20 \%$ paper mulberry silage, PMS30: dietary with $30 \%$ paper mulberry silage, PMS40: dietary with $40 \%$ paper mulberry silage. The colour of LD: L*(lightness), $a^{*}$ (redness), $b^{*}$ (yellowness). SEM, standard error of the mean. ab Mean values in the same row (corresponding to the same variable) with different letter differ significantly $(p<0.05)$.

\subsection{Rumen Fermentation Characteristics and VFA Composition Serum Biochemistry}

PMS40 significantly increased $(p<0.05)$ rumen microbial protein $(\mathrm{MCP})$ compared with other groups. However, significant difference between control, PMS20 and PMS30 was not detected. PMS30 significantly affected the A/P ratio of rumen $(p<0.05)$, but rumen $\mathrm{pH}, \mathrm{AN}$ and other individual volatile fatty acids (VFA) proportion did not differ $(p>0.05)$ 
among treatments (Table 3). No effect of dietary PMS on serum biochemical indices was observed in Hu lambs (Table 4).

Table 3. Effect of dietary paper mulberry silage on rumen fermentation characteristics of Hu lambs.

\begin{tabular}{|c|c|c|c|c|c|c|}
\hline Item & Control & PMS20 & PMS30 & PMS40 & SEM & $p$-Value \\
\hline \multicolumn{7}{|c|}{ Fermentation characteristics } \\
\hline $\mathrm{pH}$ & 6.92 & 6.97 & 7.15 & 7.12 & 0.1521 & 0.390 \\
\hline $\mathrm{MCP} \mathrm{mg} / \mathrm{mL}$ & $1.29 \mathrm{~b}$ & $1.73 \mathrm{ab}$ & $1.70 \mathrm{ab}$ & $1.85 \mathrm{a}$ & 0.1092 & $<0.001$ \\
\hline $\mathrm{AN} \mathrm{mmol} / \mathrm{L}$ & 8.84 & 7.04 & 5.70 & 6.96 & 1.1236 & 0.120 \\
\hline TVFA mmol/L & $47.09 \mathrm{a}$ & $28.52 \mathrm{~b}$ & $20.26 \mathrm{~b}$ & $22.92 \mathrm{~b}$ & 6.3702 & 0.012 \\
\hline \multicolumn{7}{|c|}{ Individual VFA, $\%$ of total VFA } \\
\hline Acetic acid & 33.00 & 31.66 & 39.51 & 35.01 & 4.4809 & 0.379 \\
\hline Propionic acid & 26.10 & 26.44 & 19.32 & 23.95 & 2.7045 & 0.099 \\
\hline Isobutyric acid & 4.60 & 6.17 & 6.03 & 7.00 & 1.1891 & 0.310 \\
\hline Butyric acid & 24.51 & 21.40 & 19.31 & 21.00 & 2.2924 & 0.227 \\
\hline Isovaleric acid & 8.72 & 11.15 & 9.48 & 12.13 & 2.3237 & 0.486 \\
\hline Valeric acid & 3.07 & 3.17 & - & - & - & 0.876 \\
\hline $\mathrm{A} / \mathrm{P}$ ratio & $1.26 \mathrm{~b}$ & $1.20 \mathrm{~b}$ & $2.05 \mathrm{a}$ & $1.46 \mathrm{~b}$ & 0.2345 & 0.025 \\
\hline
\end{tabular}

Control: dietary without paper mulberry silage, PMS20: dietary with 20\% paper mulberry silage, PMS30: dietary with $30 \%$ paper mulberry silage, PMS40: dietary with $40 \%$ paper mulberry silage. MCP, microbial protein; AN, Ammonia nitrogen; TVFA, Total volatile fatty acids; $\mathrm{A} / \mathrm{P}$ ratio, acetic acid/propionic acid. ab Mean values in the same row (corresponding to the same variable) with different letter differ significantly $(p<0.05)$.

Table 4. Effect of dietary paper mulberry silage on serum biochemical indices of $\mathrm{Hu}$ lambs.

\begin{tabular}{ccccccc}
\hline Item & Control & PMS20 & PMS30 & PMS40 & SEM & $p$-Value \\
\hline GH ng/mL & 0.93 & 1.04 & 1.27 & 1.52 & 0.4111 & 0.522 \\
INS mIU/L & 21.07 & 24.65 & 32.02 & 28.15 & 5.2176 & 0.260 \\
GLU (mmol/L) & 3.89 & 4.09 & 4.17 & 4.77 & 0.4666 & 0.334 \\
TC (mmol/L) & 1.44 & 1.30 & 1.51 & 1.78 & 0.1724 & 0.108 \\
TG (mmol/L) & 0.31 & 0.19 & 0.25 & 0.23 & 0.0349 & 0.055 \\
HDL (mmol/l) & 0.70 & 0.71 & 0.74 & 0.74 & 0.0681 & 0.919 \\
LDL (mmol/l) & 0.88 & 0.86 & 0.91 & 1.02 & 0.1105 & 0.518 \\
NEFA $(\mu \mathrm{mol} / \mathrm{L})$ & 191.86 & 192.29 & 197.08 & 203.35 & 12.9157 & 0.794 \\
LEP $(\mathrm{ng} / \mathrm{mL})$ & 1.98 & 1.93 & 2.02 & 1.94 & 0.1122 & 0.827 \\
\hline
\end{tabular}

Control: dietary without paper mulberry silage, PMS20: dietary with $20 \%$ paper mulberry silage, PMS30: dietary with $30 \%$ paper mulberry silage, PMS40: dietary with $40 \%$ paper mulberry silage. GH, growth hormone; INS, insulin; GLU, glucose; TC, total cholesterol; TG, triglyceride; High-density lipoproteins; LDL, Low-density lipoproteins; NEFA, non-esterified fatty acid; LEP, leptin.

\subsection{Amino Acid Composition of Longissimus Dorsi Muscle}

The free amino acid composition of LD muscle was summarized in Table 5. PMS20, PMS30 and PMS40 groups had no significant difference $(p>0.05)$ in terms of most amino acids components, but resulted in a significant increase $(p<0.05)$ in Met and Tyr, and decrease Gln levels. Overall, there are no significant differences on essential amino acids (EAA) and total amino acids (TAA).

\subsection{Fatty Acid Composition of Longissimus Dorsi Muscle}

As shown in Table 6, the content of cis-15-tetracosenoic acid (C24:1, Nervonic acid) was significantly higher in PMS30 and PMS40 than control $(p<0.05)$. Docosadienoic acid $(\mathrm{C} 22: 2 \mathrm{n}-6)$ was significantly lower in PMS20 and PMS40 than control $(p<0.05)$. PMS40 increased $(p<0.05)$ the proportions of eicosapentaenoic acid (C20:5n-3, EPA).

\subsection{Rumen Bacterial Diversity and Correlation Analysis of Meat Fatty Acids and Free Amino Acids}

The $16 \mathrm{~S}$ rDNA fragments covering the variable V3 and V4 regions were PCR amplified and sequenced. In Table 7 , the coverage of all samples was $>0.99$, indicating that the sequencing depth was sufficient to reveal the complete bacterial diversity of rumen liquid 
samples. Alpha diversity indicated that paper mulberry silage did not significantly affect shannon, simpson, ace, and chao indices $(p>0.05)$.

Table 5. Effect of dietary Paper mulberry silage on free amino acids composition of longissimus dorsi (LD) muscle of $\mathrm{Hu}$ lambs ( $\mathrm{mg} / \mathrm{g}$ of frozen dry basis).

\begin{tabular}{ccccccc}
\hline Item (mg/g) & Control & PMS20 & PMS30 & PMS40 & SEM & $p$-Value \\
\hline Methionine (Met) & $0.0230 \mathrm{~b}$ & $0.0265 \mathrm{~b}$ & $0.0248 \mathrm{~b}$ & $0.0337 \mathrm{a}$ & 0.0029 & 0.029 \\
Lysine (Lys) & 0.1603 & 0.1226 & 0.1276 & 0.1498 & 0.0029 & 0.381 \\
Valine (Val) & 0.0927 & 0.0748 & 0.0784 & 0.0988 & 0.0235 & 0.226 \\
Isoleucine (Ile) & 0.0618 & 0.0568 & 0.0555 & 0.0739 & 0.0121 & 0.216 \\
Phenylalanine (Phe) & 0.0537 & 0.0486 & 0.0492 & 0.0617 & 0.0087 & 0.113 \\
Leucine (Leu) & 0.0947 & 0.0867 & 0.0863 & 0.1122 & 0.0052 & 0.207 \\
Tryptophan (Trp) & 0.0225 & 0.0186 & 0.0190 & 0.0245 & 0.0124 & 0.181 \\
Threonine (Thr) & 0.1682 & 0.0966 & 0.1406 & 0.1220 & 0.0028 & 0.155 \\
EAA & 0.6768 & 0.5311 & 0.5814 & 0.4444 & 0.0282 & 0.615 \\
Histidine (His) & 0.0475 & 0.0595 & 0.0585 & 0.0764 & 0.1729 & 0.164 \\
Arginine (Arg) & 0.4001 & 0.2208 & 0.2348 & 0.2478 & 0.0113 & 0.082 \\
Asparagic acid (Asp) & 0.0236 & 0.0491 & 0.0582 & 0.0447 & 0.0658 & 0.420 \\
Asparagine (Asn) & 0.1020 & 0.0854 & 0.0996 & 0.1220 & 0.0202 & 0.299 \\
Tyrosine (Tyr) & $0.0826 \mathrm{ab}$ & $0.0716 \mathrm{bc}$ & $0.0703 \mathrm{c}$ & $0.0912 \mathrm{a}$ & 0.0177 & 0.010 \\
Alanine (Ala) & 1.5181 & 1.2091 & 1.3683 & 1.5010 & 0.0051 & 0.583 \\
Proline (Pro) & 0.1423 & 0.1094 & 0.1204 & 0.1438 & 0.2440 & 0.074 \\
Serine (Ser) & 0.1691 & 0.1369 & 0.1356 & 0.1578 & 0.0130 & 0.343 \\
Cysteine (Cys) & 0.0047 & 0.0062 & 0.0002 & 0.0001 & 0.0204 & 0.714 \\
Glutamic acid (Glu) & 0.1024 & 0.0920 & 0.1967 & 0.0993 & 0.0540 & 0.246 \\
Glutamine (Gln) & $9.1478 \mathrm{a}$ & $5.2928 \mathrm{~b}$ & $5.9348 \mathrm{~b}$ & $4.9756 \mathrm{~b}$ & 1.2693 & 0.038 \\
Glycine (Gly) & 0.9312 & 0.6978 & 0.7961 & 0.7230 & 0.1132 & 0.241 \\
TAA & 12.6715 & 8.0266 & 9.0734 & 5.1777 & 2.3571 & 0.072 \\
EAA/TAA & 0.0536 & 0.0673 & 0.0673 & 0.0840 & 0.0104 & 0.105 \\
\hline
\end{tabular}

Control: dietary without paper mulberry silage, PMS20: dietary with 20\% paper mulberry silage, PMS30: dietary with $30 \%$ paper mulberry silage, PMS40: dietary with $40 \%$ paper mulberry silage. EAA, essential amino acid $(\mathrm{EAA}=\mathrm{Met}+\mathrm{Lys}+\mathrm{Val}+\mathrm{Ile}+\mathrm{Phe}+\mathrm{Leu}+\mathrm{Trp}+\mathrm{Thr}) ; \mathrm{TAA}$, total amino acid. abc Mean values in the same row (corresponding to the same variable) with different letter differ significantly $(p<0.05)$.

19 bacterial phylum were identified among all the rumen liquid samples, with Bacteroidetes, Firmicutes, Synergistetes, and Spirochaetota being the four most predominant phyla, each of which was represented by more than $0.01 \%$ of the total sequences in at least one group (Supplementary Figure S1). The relative abundance of Bacteroidota in Control, PMS20, PMS30, and PMS40 were 62.74\%, 62.34\%, 54.54\%, and 49.58\%, respectively. Additionally, PMS30 and PMS40 groups not only had a highly abundance $(41.38 \%, 46.81 \%)$ of Firmicutes than control and PMS20 group (32.04\%, 32.31\%), but they also decreased relative abundance of Synergistetes $(0.23 \%, 0.39 \%)$ in PMS30 and PMS40 groups. However, no significant difference in all the changes at the phylum level (Supplementary Figure S2A) was found. Ruminal bacterial community composition based on genus level was shown in Figure 1, and Prevotella and Rikenellaceae_RC9_gut_group were predominant genera in all groups. Only Christensenellaceae_R-7_group and norank_f_Eubacterium_coprostanoligenes_group were showed a significant difference $(p<0.05)$ among the four groups (Supplementary Figure S2B).

To further study how bacteria change muscle fatty acids composition, we explored the relationship between ruminal bacterial community and fatty acids profiles. The results suggested that relative abundance of the Christensenellaceae_R-7_group, norank_f_Bacteroidales_ BS11_gut_group and Ruminococcus_gauvreauii_group were positively correlated with the content of TFA, SFA and n-3 PUFA (Figure 2). However, Treponema was negatively correlated with C24:1, TFA, SFA, and Fretibacterium was also negatively correlated with C20:5n-3 and n-3 PUFA. Besides, norank_f_Selenomonadaceae and norank_f_norank_o_Bacteroidales were positively correlated with ratio of n-6/n-3, while unclassified_f_Ruminococcaceae and norank_f_norank_o_Clostridia_vadin BB60_group showed an opposite result. Interestingly, the data in Figure 3 showed that Butyrivibrio was positively correlated with the content of Thr, 
Arg, Pro, Ser, Cys, and Glu. Overall, it was also suggested that Christensenellaceae_R-7_group, Saccharofermentans, unclassified_f_Ruminococcaceae, Ruminococcus_gauvreauii_group, Eubacterium_ruminantium_group, Lachnospiraceae_XPB1014_group, Anaerovorax, and norank_f_ Lachnospiraceae were positively correlated with free amino acids.

Table 6. Effect of dietary paper mulberry silage on fatty acid composition of longissimus dorsi muscle of Hu lambs (mg/g of frozen dry basis).

\begin{tabular}{|c|c|c|c|c|c|c|}
\hline Item (mg/g) & Control & PMS20 & PMS30 & PMS40 & SEM & $p$-Value \\
\hline \multicolumn{7}{|c|}{ Saturated fatty acids } \\
\hline C10:0 & 0.0254 & 0.0406 & 0.0646 & 0.0707 & 0.0296 & 0.435 \\
\hline $\mathrm{C} 12: 0$ & 0.0568 & 0.0777 & 0.1125 & 0.0946 & 0.0539 & 0.763 \\
\hline $\mathrm{C} 13: 0$ & 0.0056 & 0.0051 & 0.0078 & 0.0053 & 0.0032 & 0.822 \\
\hline C14:0 & 0.7042 & 1.0344 & 1.4448 & 1.5433 & 0.5895 & 0.499 \\
\hline C15:0 & 0.0766 & 0.0887 & 0.1642 & 0.1196 & 0.0695 & 0.615 \\
\hline $\mathrm{C} 16: 0$ & 6.5970 & 9.0261 & 11.7081 & 13.0721 & 3.0069 & 0.220 \\
\hline $\mathrm{C} 17: 0$ & 0.2440 & 0.3309 & 0.5301 & 0.4043 & 0.1694 & 0.433 \\
\hline C18:0 & 4.6215 & 6.2407 & 9.6737 & 8.5631 & 2.5565 & 0.268 \\
\hline C20:0 & 0.0236 & 0.0260 & 0.0500 & 0.0396 & 0.0177 & 0.452 \\
\hline C21:0 & 0.0140 & 0.0123 & 0.0156 & 0.0133 & 0.0024 & 0.597 \\
\hline $\mathrm{C} 22: 0$ & 0.0353 & 0.0333 & 0.0399 & 0.0352 & 0.0046 & 0.549 \\
\hline $\mathrm{C} 23: 0$ & 0.1458 & 0.1524 & 0.1507 & 0.1528 & 0.0117 & 0.926 \\
\hline C24:0 & 0.1402 & 0.1401 & 0.1445 & 0.1391 & 0.0033 & 0.411 \\
\hline \multicolumn{7}{|c|}{ Monounsaturated fatty acids } \\
\hline $\mathrm{C} 14: 1$ & 0.0343 & 0.0359 & 0.0358 & 0.0532 & 0.0227 & 0.816 \\
\hline C15:1 & 0.0094 & 0.0123 & 0.0138 & 0.0120 & 0.0028 & 0.512 \\
\hline C16:1 & 0.5738 & 0.6492 & 0.7535 & 0.9969 & 0.2839 & 0.507 \\
\hline C17:1 & 0.1803 & 0.2213 & 0.2310 & 0.2663 & 0.0734 & 0.715 \\
\hline tran-9 C18:1 & 0.6095 & 0.7929 & 1.4129 & 0.9099 & 0.5060 & 0.472 \\
\hline cis-9 C18:1 & 3.9727 & 10.4094 & 13.8285 & 15.3058 & 8.5615 & 0.582 \\
\hline C20:1 & 0.0718 & 0.0687 & 0.0859 & 0.0739 & 0.0128 & 0.582 \\
\hline C22:1 & 0.2062 & 0.2148 & 0.2071 & 0.2104 & 0.0076 & 0.672 \\
\hline $\mathrm{C} 24: 1$ & $0.0840 \mathrm{~b}$ & $0.0901 \mathrm{ab}$ & $0.0978 \mathrm{a}$ & $0.0957 \mathrm{a}$ & 0.0044 & $<0.05$ \\
\hline \multicolumn{7}{|c|}{$\begin{array}{l}\text { n-6 Polyunsaturated fatty } \\
\text { acids }\end{array}$} \\
\hline $\mathrm{C} 18: 2 \mathrm{n}-6 t$ & 0.0386 & 0.0409 & 0.0736 & 0.0785 & 0.0239 & 0.273 \\
\hline$C 18: 2 n-6 c$ & 2.4999 & 3.1150 & 3.9036 & 3.4094 & 0.7755 & 0.389 \\
\hline$C 18: 3 n-6$ & 0.0278 & 0.0344 & 0.0411 & 0.0449 & 0.0074 & 0.185 \\
\hline$C 20: 2 n-6$ & 0.0216 & 0.0219 & 0.0338 & 0.0320 & 0.0113 & 0.603 \\
\hline$C 20: 3 n-6$ & 0.0878 & 0.0909 & 0.1062 & 0.0984 & 0.0133 & 0.544 \\
\hline$C 20: 4 n-6$ & 1.4410 & 1.5550 & 1.4913 & 1.5319 & 0.2396 & 0.965 \\
\hline $\mathrm{C} 22: 2 \mathrm{n}-6$ & $0.0202 \mathrm{a}$ & $0.0179 \mathrm{c}$ & $0.0192 \mathrm{ab}$ & $0.0184 \mathrm{bc}$ & 0.0004 & $<0.05$ \\
\hline \multicolumn{7}{|c|}{$\begin{array}{c}\text { n-3 Polyunsaturated fatty } \\
\text { acids }\end{array}$} \\
\hline C18:3n-3 & 0.0793 & 0.1163 & 0.1943 & 0.1814 & 0.0592 & 0.246 \\
\hline$C 20: 3 n-3$ & 0.0596 & 0.0597 & 0.0617 & 0.0615 & 0.0010 & 0.158 \\
\hline C20:5n-3 & $0.0804 \mathrm{~b}$ & $0.0831 \mathrm{~b}$ & $0.0881 \mathrm{ab}$ & $0.1169 \mathrm{a}$ & 0.0128 & $<0.05$ \\
\hline C22::6n-3 & 0.0944 & 0.0870 & 0.0903 & 0.0905 & 0.0104 & 0.914 \\
\hline \multicolumn{7}{|l|}{ Sum and ratio } \\
\hline TFA & 22.8826 & 34.9255 & 46.8760 & 47.8413 & 15.2287 & 0.374 \\
\hline SFA & 12.6900 & 17.2084 & 24.1066 & 24.2532 & 6.3640 & 0.271 \\
\hline MUFA & 5.7420 & 12.4947 & 16.6662 & 17.9242 & 9.1259 & 0.566 \\
\hline PUFA & 4.4506 & 5.2223 & 6.1032 & 5.6639 & 0.9630 & 0.414 \\
\hline n-3 PUFA & 0.3137 & 0.3462 & 0.4344 & 0.4503 & 0.0693 & 0.218 \\
\hline n-6 PUFA & 4.1369 & 4.8761 & 5.6688 & 5.2136 & 0.9027 & 0.432 \\
\hline n-3 LCPUFA & 0.2344 & 0.2299 & 0.2400 & 0.2688 & 0.0206 & 0.300 \\
\hline n-6 LCPUFA & 1.5706 & 1.6857 & 1.6505 & 1.6808 & 0.2498 & 0.963 \\
\hline$n-6 / n-3$ & 13.0844 & 14.1089 & 13.0893 & 11.7549 & 1.0890 & 0.271 \\
\hline $\mathrm{U} / \mathrm{S}$ & 0.8328 & 0.9815 & 0.9451 & 0.9220 & 0.3323 & 0.973 \\
\hline $\mathrm{P} / \mathrm{S}$ & 0.3539 & 0.3060 & 0.2741 & 0.2478 & 0.0433 & 0.164 \\
\hline
\end{tabular}

Control: dietary without paper mulberry silage, PMS20: dietary with 20\% paper mulberry silage, PMS30: dietary with $30 \%$ paper mulberry silage, PMS40: dietary with 40\% paper mulberry silage. SEM, standard error means; abc Mean values in the same row (corresponding to the same variable) with different letter differ significantly $(p<0.05)$.; TFA, total fatty acids $=$ saturated fatty acids $(10: 0+12: 0+13: 0+14: 0+$ $15: 0+16: 0+17: 0+18: 0+20: 0+21: 0+22: 0+23: 0+24: 0)+$ monounsaturated fatty acids $(14: 1+15: 1+16: 1+17: 1+$ trans-9 $18: 1+$ cis-9 $18: 1+$ $20: 1+22: 1+24: 1)+$ polyunsaturated fatty acids $(18: 2 n-6 t+18: 2 n-6 c+18: 3 n-6+20: 2 n-6+20: 3 n-6+20: 4 n-6+22: 2 n-6+18: 3 n-3+20: 3 n-3+$ 20:5n-3 + 22:6n-3); SFA saturated fatty acids $(10: 0+11: 0+12: 0+13: 0+14: 0+15: 0+16: 0+17: 0+18: 0+20: 0+21: 0+22: 0+23: 0+24: 0)$; MUFA monounsaturated fatty acids (14:1 + 15:1 + 16:1 + 17:1 + tran-9 18:1 + cis-9 18:1 + 20:1 + 22:1 + 24:1); n-6 PUFA, n-6 polyunsaturated fatty acids $(18: 2 n-6 t+18: 2 n-6 c+18: 3 n-6+20: 2 n-6+20: 3 n-6+20: 4 n-6+22: 2 n-6) ; n-3$ PUFA, $n-3$ polyunsaturated fatty acids (18:3n-3 + 20:3n-3 + 20:5n-3 + 22:6n-3); n-6 LCPUFA, n-6 long chain polyunsaturated fatty acids (20:2n-6 +20:3n-6 + 20:4n-6 + 22:2n-6), n-3 LCPUFA $\mathrm{n}-3$ long chain polyunsaturated fatty acids (20:3n-3 +20:5n-3 + 22:6n-3); $-6 / n-3, n-6$ long chain polyunsaturated fatty acids/n-3 long chain polyunsaturated fatty acids; U/S unsaturated fatty acids/saturated fatty acids; $\mathrm{P} / \mathrm{S}$ polyunsaturated fatty acids/saturated fatty acids. 
Table 7. Alpha diversity indices of ruminal bacteria in Hu lambs fed with different diets.

\begin{tabular}{ccccccc}
\hline Indices & Control & PMS20 & PMS30 & PMS40 & SEM & $p$-Value \\
\hline OTUs & 154 & 160 & 165 & 173 & 11.74 & 0.455 \\
Shannon & 3.1067 & 3.0509 & 3.0864 & 3.3156 & 0.2927 & 0.419 \\
Simpson & 0.1003 & 0.1350 & 0.1169 & 0.0735 & 0.0533 & 0.309 \\
Ace & 191.2942 & 187.7711 & 193.1980 & 205.1482 & 13.7368 & 0.268 \\
Chao & 231.4690 & 195.4962 & 202.4630 & 211.9072 & 24.2926 & 0.201 \\
Coverage & 0.9985 & 0.9988 & 0.9989 & 0.9987 & 0.0001 & 0.297 \\
\hline
\end{tabular}

Control: dietary without paper mulberry silage, PMS20: dietary with 20\% paper mulberry silage, PMS30: dietary with $30 \%$ paper mulberry silage, PMS40: dietary with $40 \%$ paper mulberry silage.
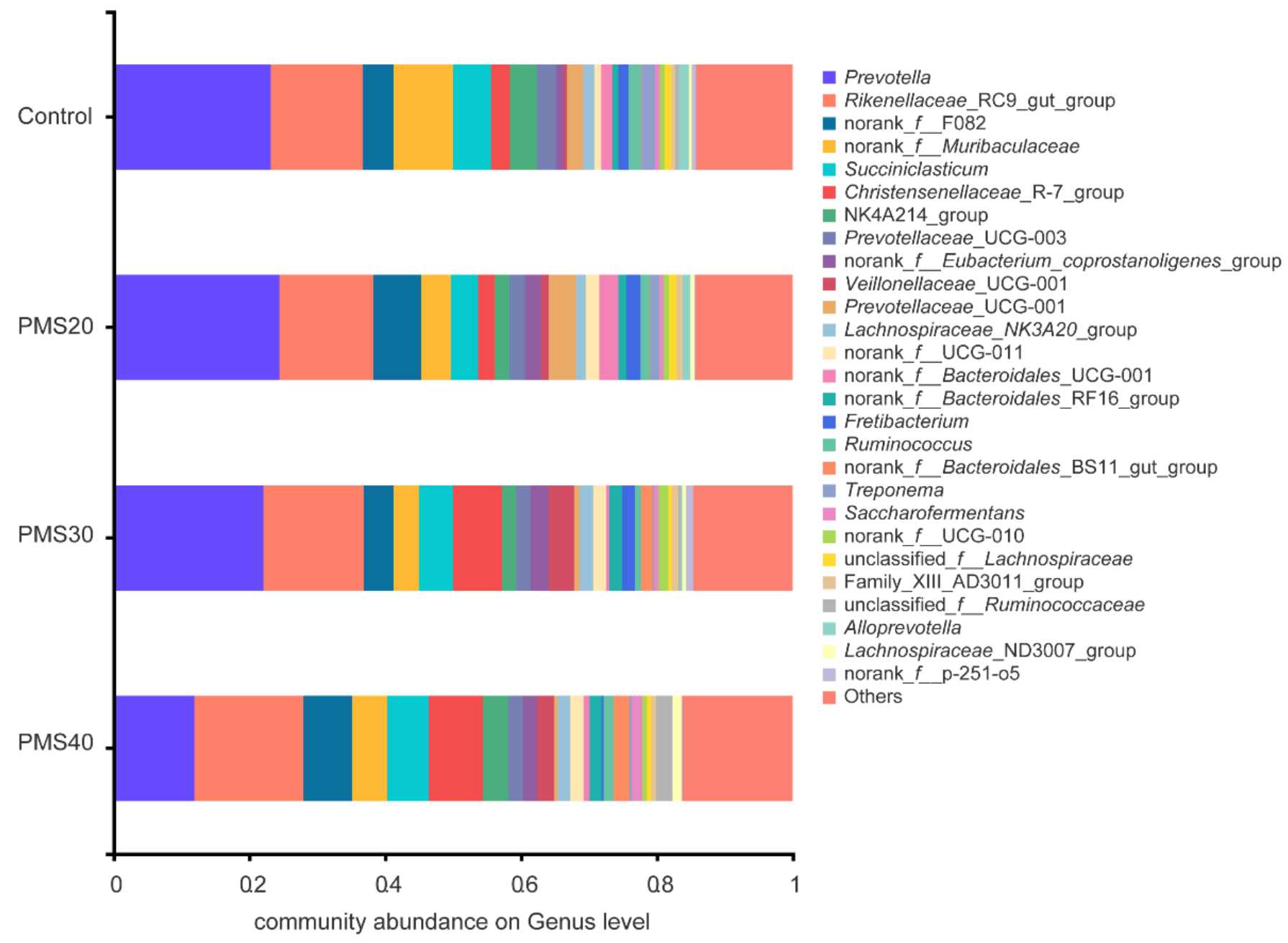

Figure 1. Paper mulberry silage changed the relative abundances on genus level of microbiota in rumen. Control: dietary without paper mulberry silage, PMS20: dietary with $20 \%$ paper mulberry silage, PMS30: dietary with $30 \%$ paper mulberry silage, PMS40: dietary with $40 \%$ paper mulberry silage.

To further study how bacteria change muscle fatty acids composition, we explored the relationship between ruminal bacterial community and fatty acids profiles. The results suggested that relative abundance of the Christensenellaceae_R-7_group, norank_f_Bacteroidales_ BS11_gut_group and Ruminococcus_gauvreauii_group were positively correlated with the content of TFA, SFA and n-3 PUFA (Figure 2). However, Treponema was negatively correlated with C24:1, TFA, SFA, and Fretibacterium was also negatively correlated with C20:5n-3 and n-3 PUFA. Besides, norank_f_Selenomonadaceae and norank_f_norank_o_Bacteroidales were positively correlated with ratio of n-6/n-3, while unclassified_f_Ruminococcaceae and norank_f_norank_o_Clostridia_vadin BB60_group showed an opposite result. Interestingly, the 
data in Figure 3 showed that Butyrivibrio was positively correlated with the content of Thr, Arg, Pro, Ser, Cys, and Glu. Overall, it was also suggested that Christensenellaceae_R-7_group, Saccharofermentans, unclassified_f_Ruminococcaceae, Ruminococcus_gauvreauii_group, Eubacterium_ruminantium_group, Lachnospiraceae_XPB1014_group, Anaerovorax, and norank_f Lachnospiraceae were positively correlated with free amino acids.

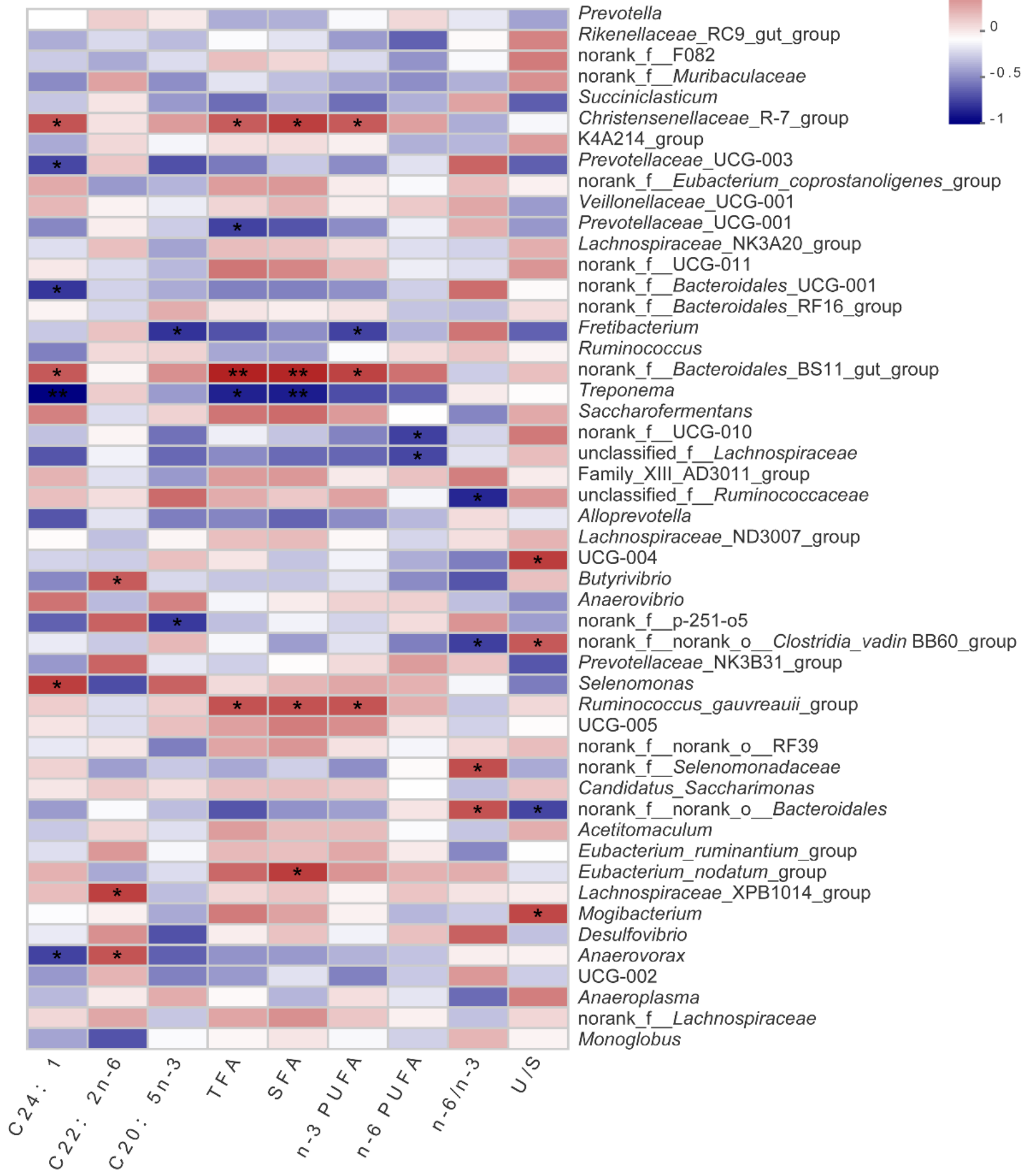

Figure 2. Heat maps of spearman correlations between the relative abundance of sequences assigned to each bacterial genus and the content of fatty acids. TFA, total fatty acids, SFA saturated fatty acids, n-3 PUFA, n-3 polyunsaturated fatty acids, n- 6 PUFA, n-6 polyunsaturated fatty acids, n- $6 / n-3, n-6$ long chain polyunsaturated fatty acids/n-3 long chain polyunsaturated fatty acids; U/S unsaturated fatty acids/saturated fatty acids. "** indicates a significant difference $(p<0.05)$, "**" indicates a significant difference $(p<0.01)$. 


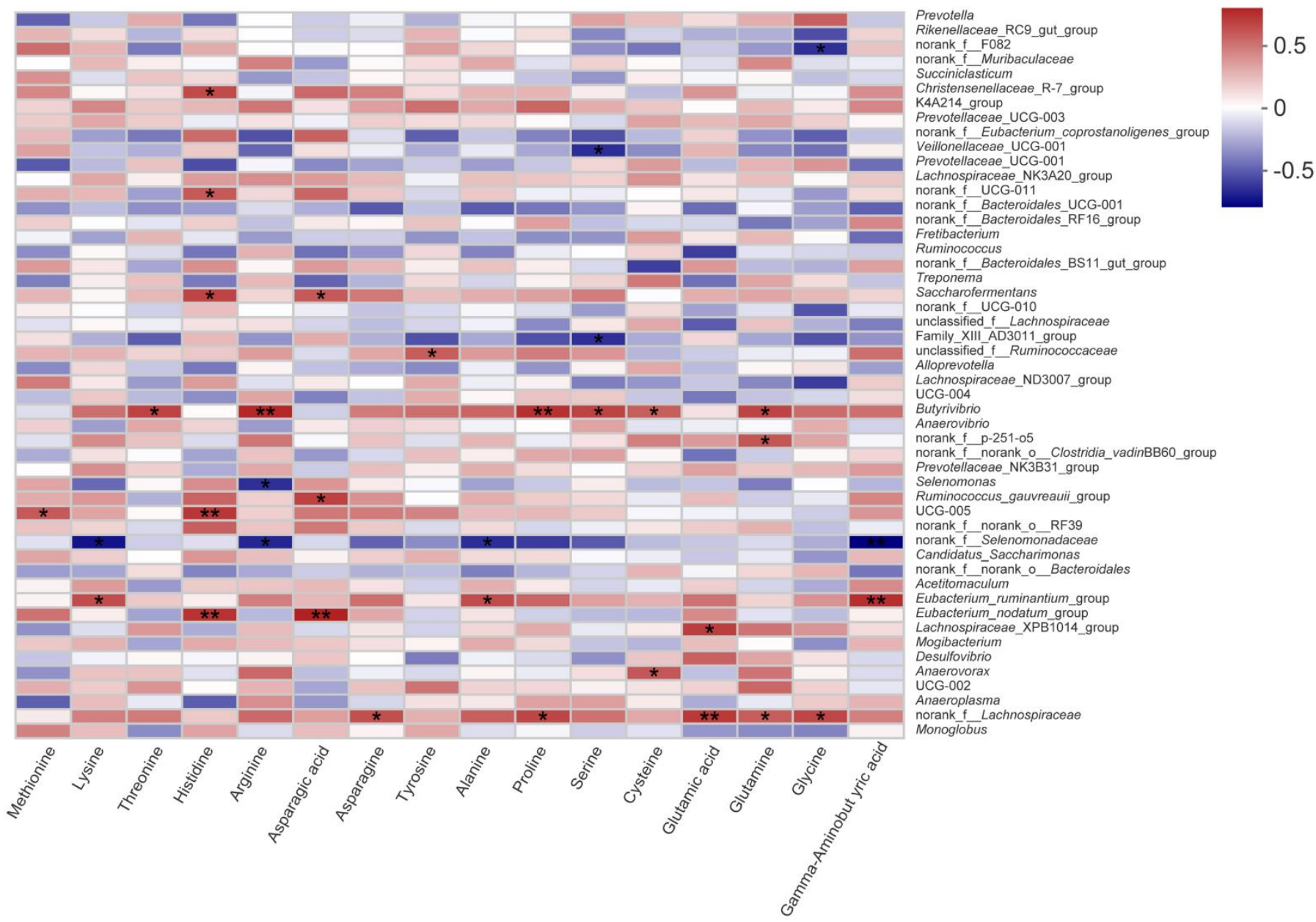

Figure 3. Heat maps of spearman correlations between the relative abundance of sequences assigned to each bacterial genus and the content of free amino acids. "** indicates a significant difference $(p<0.05)$, " "*” indicates a significant difference $(p<0.01)$.

\section{Discussion}

In the present study, PMS30 and PMS40 contained higher DMI and ADG than others, which was similar to the results in goats, sheep, and beef cattle fed with paper mulberry or paper mulberry silage $[14,15,24]$. This might be due to the replacement of low quality corn stover with high quality silage in the diets for $\mathrm{Hu}$ lambs, and it was also consistent with the result reported by Tao that PMS could increase the DMI in beef cattle [24]. DMI in ruminants have been associated with neutral detergent fiber (NDF) content in diets [25-27]. A negative correlation between NDF content and DMI in dairy cow diets has also been found [28]. Miller et al. also reported that cows fed with higher NDF diet consumed less DM than cows fed with lower NDF diet [29]. In general, this observation could be explained by the lower NDF content of PMS30 and PMS40 group compared with Control.

Serum biochemical indices reflect the health status and nutrients utilization of livestock [24]. Si and Tao reported that PMS had no effects on the serum metabolites of cow and beef cattle [18,24], and similar results were found in the present study, which suggested that lambs were in healthy status with no adverse effects on their performance. Therefore, in this study, PMS had no negative effects on the growth and metabolism of Hu lambs.

$\mathrm{AN}$ is primarily used by microorganisms as raw material for producing $\mathrm{MCP}$, an important source of high quality protein for ruminants [30], as well as the end product of nitrogenous compound in mixed ration [31,32]. In this study, AN was at a reasonable 
concentration level [33]. It was not conducive to the growth of rumen microorganisms with neither too high nor too low concentration of AN in rumen. Ruminants principally rely on the small intestine to absorb protein, which primarily comes from MCP and rumen bypass protein. PMS40 had a higher MCP than other groups. This observation is consistent with the previous study that MCP synthesis was increased in goat fed with $45 \%$ paper mulberry of diet [14]. Therefore, higher content of PMS was speculated to synthesize more $\mathrm{MCP}$ in rumen. TFA concentration was affected by the forage offered [34]. It was found that PMS would lead to a lower TVFA in rumen before slaughter. This may be due to the high digestibility of PMS, which can pass through rumen faster [11]. In all treatments, the rumen TVFA content decreased after $12 \mathrm{~h}$ of fasting.

The meat quality of Hu lamb was not affected by PMS in the present study, which is consistent with the previous study in Hu rams after being fed with paper mulberry [15]. However, the previous study showed that paper mulberry could improve the meat quality of goats compared to maize silage [14]. Based on this, the response of meat quality to the PMS might mainly be affected by animal species.

We further studied the effects of PMS on fatty and amino acids in the LD muscle of lambs. Because of the active substances such as polyphenols, herbs and shrubs are generally used to improve the flavor of meat compared to crops [19]. In the present study, we found that PMS40 feeding did not change the concentration of free amino acid except for Met and Tyr. It is noteworthy that flavor amino acid (glycine, alanine, serine, threonine, glutamic acid, and aspartic acid), which play an important role in determining the acceptability and directly affects meat taste, also showed no significant differences among the treatments in the present study. Although polyphenols and tannin, when possibly being considered rich in paper mulberry, were considered that could lead to a high content of rumen-protected protein, and the previous study also reported that PMS might not affect amino acid metabolism [24]. It might be related to the type, erratic and dose-dependent responses of tannins in the paper mulberry silage diet [8].

Fatty acid profiles of LD muscle also play a key role in meat quality [35], and in particular, n-3 fatty acids are considered as functional FA to prevent non-alcoholic fatty liver disease (NAFLD) and Obesity. In the present study, PMS40 diet led to an increase of C24:1 and C20:5n-3(EPA). To the best to our knowledge, ruminal bio-hydrogenation $\mathrm{BH})$ promotes the accumulation of saturated FA in ruminant meat. Therefore, reducing rumen $\mathrm{BH}$ has become an important way to improve meat quality. Evidence supports the effect of tannin's regulation of rumen lipid metabolism on meat polyunsaturated fatty acids (PUFA) [8]. Based on this, paper mulberry may have the potential to reduce rumen $\mathrm{BH}$ and improve meat quality because of the high concentration of condensed tannin [11]. It seems that the reasons for these different observations are not clear yet, and the underlying lipids metabolism mechanism of rumen needs to be clarified in the future study.

Forage-based or grain-based diet, and even starch type and tannin content of feed could affect rumen fermentation and meat quality $[13,36,37]$. Therefore, we proposed that ruminal bacteria may indirectly influence the fatty acids in the muscle through the interaction between rumen bacteria and the host. At the phylum level, PMS30 and PMS40 had a lower spirochete abundance than others, which may lead to healthier body condition than the control group [38]. PMS30 and PMS40 could result in a significant impact on rumen bacterial community. Although Christensenellaceae _R-7_group and norank_f_Eubacterium_coprostanoligenes_group were significantly higher in PMS30 and PMS40 than control group (Supplementary Figure S2), very few studies have focused on the metabolism of Eubacterium_coprostanoligenes. It had also been found in the rumen of high-yield dairy cows after being fed with Perilla frutescens leaves reported by Sun [39]. In the present study, it was indicated that Christensenellaceae_R-7_group and norank_f_Eubacterium_coprostanoligenes_group may have the largest contribution to the improvement of LD fatty acid distribution and growth performance via PMS diet. Then, Christensenellaceae is mostly affected by the host genetic which may be beneficial to the 
body health [40], and besides, we also found that Christensenellaceae_R-7_group, norank $\_$_ Bacteroidales_BS11_gut_group and Ruminococcus_gauvreauii_group were positively correlated with TFA, SFA, and n-3 PUFA. Besides, BS11 are cosmopolitan host-associated bacteria prevalent in ruminant gastrointestinal tracts, and it is also reported that they may play an important role in the degradation of recalcitrant carbohydrates and provide beneficial metabolites to host metabolism [41]. In addition, Solden had identified BS11 that become dominant in rumen when the host consumes a high woody biomass diet [42], which was verified in our research because paper mulberry is a typical woody plant. The $R u-$ minococcus spp. has been considered as a crucial cellulolytic bacteria generally detected in rumen [43]. Ruminococcus_gauvreauii_group showed no significant difference between treatments, but a positive correlation with fatty acid was found, especially n-3PUFA (Figure 2). Rumen fermentation and metabolism are not only affected by dietary protein, structural carbohydrates, and starch, but also related to active metabolites such as flavonoids, tannins, and saponins, which can regulate the activities of microorganisms. Taking into account the correlation among paper mulberry silage, rumen bacterial community and fatty acids, we prefer that PMS improve fatty acids distribution in LD by changing rumen microbe composition and metabolic pathways. Unlike fatty acids, the changes in amino acids did not seem to be affected by rumen bacterial community in this study, although Butyrivibrio, Eubacterium spp. and norank_f_Lachnospiraceae had a positive correlation with some amino acids. To the best of our knowledge, amino acids are mainly absorbed in the small intestine, so protein passing through rumen has become an important research direction for amino acid metabolism [44]. Tannins are widely reported to reduce rumen BH, protect rumen protein degradation and reduce methane production $[8,45,46]$. However, paper mulberry rich in tannins did not generate the expected results in amino acids of $L D$, probably because silage reduced the tannin content. Increasing research has been conducted to study not only which bacterial community are changing in rumen but also the functional metabolites shifting. Concomitantly, further study is still necessary to explore the relationship between rumen microorganism composition, rumen metabolites, and amino acid metabolism via metagenomics and metabolome.

\section{Conclusions}

PMS40 could improve the growth performance and meat fatty acids profiles of $\mathrm{Hu}$ lambs, which might lead to a relatively high content of unsaturated fatty acids in longissimus dorsi muscle by increasing the relative abundance of Christensenellaceae_R-7_group in rumen.

Supplementary Materials: The following are available online at https:/ / www.mdpi.com/article/10 .3390 / fermentation7040286/s1, Figure S1: The relative abundance of microbial community at the phylum level, Figure S2: One-way ANOVA of microbial community of PMS treatments.

Author Contributions: Conceptualization, K.N. and F.Y.; methodology, K.N.; software, Y.X.; validation, Y.X., C.G. and L.W.; formal analysis, Y.X.; investigation, Y.X. and X.D.; resources, F.C., X.L.; data curation, Y.X.; writing-original draft preparation, Y.X.; writing-review and editing, K.N.; visualization, F.Y.; supervision, F.Y.; project administration, F.Y.; funding acquisition, F.Y. All authors have read and agreed to the published version of the manuscript.

Funding: This research was funded by the Research and Demonstration of Key Technologies for Efficient Planting, Processing and Utilization of Hybrid Paper Mulberry in Hills and Mountains (CSTC2020NGZX0000), and "Strategic Priority Research Program" of the Chinese Academy of Sciences (Grant No. XDA27040203).

Institutional Review Board Statement: The experiment was conducted in accordance with the Chinese Guidelines for Animal Welfare and Experimental Protocol, and approved by the Animal Care and Use Committee of China Agricultural University (ID: AW22601202-5-1).

Informed Consent Statement: Not applicable.

Data Availability Statement: The data presented in this study are available on request from the first author. The data are not publicly available due to restrictions by the research group. 
Acknowledgments: The authors gratefully acknowledge the staff of Rongcheng Gouyang Modern Agriculture Co., Ltd.

Conflicts of Interest: The authors declare no conflict of interest.

\section{References}

1. Jiang, Y.; Xie, M.; Chen, W.; Talbot, R.; Maddox, J.F.; Faraut, T.; Wu, C.; Muzny, D.M.; Li, Y.; Zhang, W.; et al. The sheep genome illuminates biology of the rumen and lipid metabolism. Science 2014, 344, 1168-1173. [CrossRef] [PubMed]

2. Kantono, K.; Hamid, N.; Ma, Q.; Chadha, D.; Oey, I. Consumers' perception and purchase behaviour of meat in China. Meat Sci. 2021, 179, 108548. [CrossRef] [PubMed]

3. Shabbir, S.; Boruah, P.; Xie, L.; Kulyar, M.F.; Nawaz, M.; Yousuf, S.; Liu, T.; Jabeen, F.; Miao, X. Genome-wide transcriptome profiling uncovers differential miRNAs and lncRNAs in ovaries of Hu sheep at different developmental stages. Sci. Rep. 2021, 11, 5865. [CrossRef]

4. Ni, K.; Wang, F.; Zhu, B.; Yang, J.; Zhou, G.; Pan, Y.; Tao, Y.; Zhong, J. Effects of lactic acid bacteria and molasses additives on the microbial community and fermentation quality of soybean silage. Bioresour. Technol 2017, 238, 706-715. [CrossRef] [PubMed]

5. Du, Z.; Sun, L.; Lin, Y.; Yang, F.; Cai, Y. The use of PacBio SMRT technology to explore the microbial network and fermentation characteristics of woody silage prepared with exogenous carbohydrate additives. J. Appl. Microbiol. 2021. [CrossRef]

6. Du, Z.; Sun, L.; Chen, C.; Lin, J.; Yang, F.; Cai, Y. Exploring microbial community structure and metabolic gene clusters during silage fermentation of paper mulberry, a high-protein woody plant. Anim. Feed. Sci. Technol. 2021, 275, 114766. [CrossRef]

7. Zhang, Y.C.; Li, D.X.; Wang, X.K.; Lin, Y.L.; Zhang, Q.; Chen, X.Y.; Yang, F.Y. Fermentation dynamics and diversity of bacterial community in four typical woody forages. Ann. Microbiol. 2019, 69, 233-240. [CrossRef]

8. Frutos, P.; Hervás, G.; Natalello, A.; Luciano, G.; Fondevila, M.; Priolo, A.; Toral, P.G. Ability of tannins to modulate ruminal lipid metabolism and milk and meat fatty acid profiles. Anim. Feed Sci. Technol. 2020, 269, 114623. [CrossRef]

9. Cai, Y.; Benno, Y.; Ogawa, M.; Ohmomo, S.; Kumai, S.; Nakase, T. Influence of Lactobacillus spp. from an inoculant and of Weissella and Leuconostoc spp. from forage crops on silage fermentation. Appl. Environ. Microbiol. 1998, 64, 2982-2987. [CrossRef]

10. McDonald, P.; Henderson, A.R.; Heron, S.J.E. The Biochemistry of Silage; Chalcombe Publications: Southampton, UK, 1991; 340p.

11. Li, R.; Zheng, M.; Jiang, D.; Tian, P.; Zheng, M.; Xu, C. Replacing alfalfa with paper mulberry in total mixed ration silages: Effects on ensiling characteristics, protein degradation, and in vitro digestibility. Animals 2021, 11, 1273. [CrossRef] [PubMed]

12. Del Bianco, S.; Natalello, A.; Luciano, G.; Valenti, B.; Campidonico, L.; Gkarane, V.; Monahan, F.; Biondi, L.; Favotto, S.; Sepulcri, A.; et al. Influence of dietary inclusion of tannin extracts from mimosa, chestnut and tara on volatile compounds and flavour in lamb meat. Meat Sci. 2021, 172, 108336. [CrossRef] [PubMed]

13. Li, Z.; Wright, A.D.; Liu, H.; Fan, Z.; Yang, F.; Zhang, Z.; Li, G. Response of the rumen microbiota of sika deer (Cervus nippon) fed different concentrations of tannin rich plants. PLoS ONE 2015, 10, e0123481. [CrossRef] [PubMed]

14. Hua, J.; Xu, T.; Shen, Q.; Liu, Y.; Wang, J. Productive and metabolic increments of the inclusion of Broussonetia papyrifera to replace maize silage in growing goats. Czech J. Anim. Sci. 2020, 65, 303-310. [CrossRef]

15. Sheng, P.; He, L.; Ji, S.; Huang, J.; Zhang, Z.; Wang, D.; Liu, J.; Zhang, H. Effect of Broussonetia papyrifera L. (paper mulberry) on growth performance, carcase traits, meat quality and immune performance in Hu ram lambs. Ital. J. Anim. Sci. 2021, 20, 691-697. [CrossRef]

16. Hao, Y.; Huang, S.; Liu, G.; Zhang, J.; Liu, G.; Cao, Z.; Wang, Y.; Wang, W.; Li, S. Effects of different parts on the chemical composition, silage fermentation profile, in vitro and in situ digestibility of paper mulberry. Animals 2021, 11, 413. [CrossRef] [PubMed]

17. Hao, Y.; Huang, S.; Si, J.; Zhang, J.; Gaowa, N.; Sun, X.; Lv, J.; Liu, G.; He, Y.; Wang, W.; et al. Effects of paper mulberry silage on the milk production, apparent digestibility, antioxidant capacity, and fecal bacteria composition in Holstein dairy cows. Animals 2020, 10, 1152. [CrossRef]

18. Si, B.; Tao, H.; Zhang, X.; Guo, J.; Cui, K.; Tu, Y.; Diao, Q. Effect of Broussonetia papyrifera L. (paper mulberry) silage on dry matter intake, milk composition, antioxidant capacity and milk fatty acid profile in dairy cows. Asian-Australas. J. Anim. Sci. 2018, 31, 1259-1266. [CrossRef]

19. Wang, B.; Wang, Y.; Zuo, S.; Peng, S.; Wang, Z.; Zhang, Y.; Luo, H. Untargeted and targeted metabolomics profiling of muscle reveals enhanced meat quality in artificial pasture grazing Tan lambs via rescheduling the rumen bacterial community. J. Agric. Food Chem. 2021, 69, 846-858. [CrossRef] [PubMed]

20. Honikel, K.O. Reference methods for the assessment of physical characteristics of meat. Meat Sci. 1998, 49, 447-457. [CrossRef]

21. Cardoso, D.B.; Medeiros, G.R.; Guim, A.; Azevedo, P.S.; Suassuna, J.M.A.; Lima, D.M.; Maciel, M.V.; Costa, C.A.; Lopes, L.A.; Silva, J.L.; et al. Growth performance, carcass traits and meat quality of lambs fed with increasing levels of spineless cactus. Anim. Feed Sci. Technol. 2021, 272, 114788. [CrossRef]

22. Xu, X.J.; Chen, X.L.; Chen, D.W.; Yu, B.; Yin, J.D.; Huang, Z.Q. Effects of dietary apple polyphenol supplementation on carcass traits, meat quality, muscle amino acid and fatty acid composition in finishing pigs. Food Funct. 2019, 10, 7426-7434. [CrossRef]

23. Zhang, J.; Qian, S.; Chen, J.; Ding, L.; Blache, D. Calm Hu ram lambs assigned by temperament classification are healthier and have better meat quality than nervous Hu ram lambs. Meat Sci. 2021, 175, 108436. [CrossRef] [PubMed] 
24. Tao, H.; Si, B.; Xu, W.; Tu, Y.; Diao, Q. Effect of Broussonetia papyrifera L. silage on blood biochemical parameters, growth performance, meat amino acids and fatty acids compositions in beef cattle. Asian-Australas. J. Anim. Sci. 2020, 33, 732-741. [CrossRef]

25. Khan, S.H.; Shahzad, M.A.; Nisa, M.; Sarwar, M. Nutrients intake, digestibility, nitrogen balance and growth performance of sheep fed different silages with or without concentrate. Trop. Anim. Health Prod. 2011, 43, 795-801. [CrossRef] [PubMed]

26. Cooke, K.M.; Bernard, J.K.; West, J.W. Performance of lactating dairy cows fed ryegrass silage and corn silage with ground corn, steam-flaked corn, or hominy feed. J. Dairy Sci. 2009, 92, 1117-1123. [CrossRef] [PubMed]

27. Kung, L.; Moulder, B.M.; Mulrooney, C.M.; Teller, R.S.; Schmidt, R.J. The effect of silage cutting height on the nutritive value of a normal corn silage hybrid compared with brown midrib corn silage fed to lactating cows. J. Dairy Sci. 2008, 91, 1451-1457. [CrossRef]

28. West, J.W.; Hill, G.M.; Fernandez, J.M.; Mandebvu, P.; Mullinix, B.G. Effects of dietary fiber on intake, milk yield, and digestion by lactating dairy cows during cool or hot, humid weather. J. Dairy Sci. 1999, 82, 2455-2465. [CrossRef]

29. Miller, M.D.; Kokko, C.; Ballard, C.S.; Dann, H.M.; Fustini, M.; Palmonari, A.; Formigoni, A.; Cotanch, K.W.; Grant, R.J. Influence of fiber degradability of corn silage in diets with lower and higher fiber content on lactational performance, nutrient digestibility, and ruminal characteristics in lactating Holstein cows. J. Dairy Sci. 2021, 104, 1728-1743. [CrossRef]

30. Storm, E.; Orskov, E.R.; Smart, R. The nutritive value of rumen micro-organisms in ruminants. 2. The apparent digestibility and net utilization of microbial $\mathrm{N}$ for growing lambs. Br. J. Nutr. 1983, 50, 471-478. [CrossRef] [PubMed]

31. Patra, A.K.; Aschenbach, J.R. Ureases in the gastrointestinal tracts of ruminant and monogastric animals and their implication in urea-N/ammonia metabolism: A review. J. Adv. Res. 2018, 13, 39-50. [CrossRef]

32. Cantalapiedra-Hijar, G.; Dewhurst, R.J.; Cheng, L.; Cabrita, A.R.J.; Fonseca, A.J.M.; Nozière, P.; Makowski, D.; Fouillet, H.; Ortigues-Marty, I. Nitrogen isotopic fractionation as a biomarker for nitrogen use efficiency in ruminants: A meta-analysis. Animal 2018, 12, 1827-1837. [CrossRef]

33. Owens, F.N.; Bergen, W.G. Nitrogen metabolism of ruminant animals: Historical perspective, current understanding and future implications. J. Anim. Sci. 1983, 57 (Suppl. S2), 498-518.

34. Mitchell, L.K.; Heinrichs, A.J. Feeding various forages and live yeast culture on weaned dairy calf intake, growth, nutrient digestibility, and ruminal fermentation. J. Dairy Sci. 2020, 103, 8880-8897. [CrossRef]

35. Simopoulos, A.P. N-3 fatty acids and human health: Defining strategies for public policy. Lipids 2001, 36, S83-S89. [CrossRef]

36. Yu, M.; Li, Z.; Rong, T.; Wang, G.; Liu, Z.; Chen, W.; Li, J.; Li, J.; Ma, X. Different dietary starch sources alter the carcass traits, meat quality, and the profile of muscle amino acid and fatty acid in finishing pigs. J. Anim. Sci. Biotechnol. 2020, 11, 78. [CrossRef]

37. Wang, X.; Martin, G.B.; Wen, Q.; Liu, S.; Li, Y.; Shi, B.; Guo, X.; Zhao, Y.; Guo, Y.; Yan, S. Palm oil protects alpha-linolenic acid from rumen biohydrogenation and muscle oxidation in cashmere goat kids. J. Anim. Sci. Biotechnol. 2020, 11, 100. [CrossRef] [PubMed]

38. Britannica, T.E.o.E. Spirochete. In Encyclopedia Britannica; Encyclopædia Britannica, Inc.: Chicago, IL, USA, 2021.

39. Sun, Z.; Yu, Z.; Wang, B. Perilla frutescens leaf alters the rumen microbial community of lactating dairy cows. Microorganisms 2019, 7, 562. [CrossRef]

40. Goodrich, J.K.; Waters, J.L.; Poole, A.C.; Sutter, J.L.; Koren, O.; Blekhman, R.; Beaumont, M.; Van Treuren, W.; Knight, R.; Bell, J.T.; et al. Human genetics shape the gut microbiome. Cell 2014, 159, 789-799. [CrossRef]

41. Solden, L.M.; Naas, A.E.; Roux, S.; Daly, R.A.; Collins, W.B.; Nicora, C.D.; Purvine, S.O.; Hoyt, D.W.; Schuckel, J.; Jorgensen, B.; et al. Interspecies cross-feeding orchestrates carbon degradation in the rumen ecosystem. Nat. Microbiol. 2018, 3, 1274-1284. [CrossRef] [PubMed]

42. Solden, L.M.; Hoyt, D.W.; Collins, W.B.; Plank, J.E.; Daly, R.A.; Hildebrand, E.; Beavers, T.J.; Wolfe, R.; Nicora, C.D.; Purvine, S.O.; et al. New roles in hemicellulosic sugar fermentation for the uncultivated Bacteroidetes family BS11. ISME J. 2017, 11, 691-703. [CrossRef]

43. Flint, H.J.; Bayer, E.A. Plant cell wall breakdown by anaerobic microorganisms from the Mammalian digestive tract. Ann. N. Y. Acad. Sci. 2008, 1125, 280-288. [CrossRef]

44. Nichols, K.; Dijkstra, J.; van Laar, H.; Kim, J.J.M.; Cant, J.P.; Bannink, A. Expression of genes related to energy metabolism and the unfolded protein response in dairy cow mammary cells is affected differently during dietary supplementation with energy from protein and fat. J. Dairy Sci. 2019, 102, 6603-6613. [CrossRef]

45. Ryel Min, B.; McTear, K.; Wang, H.H.; Joakin, M.; Gurung, N.; Abrahamsen, F.; Solaiman, S.; Sue Eun, J.; Hon Lee, J.; Dietz, L.A.; et al. Influence of elevated protein and tannin-rich peanut skin supplementation on growth performance, blood metabolites, carcass traits and immune-related gene expression of grazing meat goats. J. Anim. Physiol. Anim. Nutr. 2020, 104, 88-100. [CrossRef]

46. Vissers, A.M.; Pellikaan, W.F.; Bouwhuis, A.; Vincken, J.P.; Gruppen, H.; Hendriks, W.H. Laminaria digitata phlorotannins decrease protein degradation and methanogenesis during in vitro ruminal fermentation. J. Sci. Food Agric. 2018, 98, 3644-3650. [CrossRef] 